\title{
Protein/Amino Acid Biochemistry, Enzymology
}

National Cancer Institute

\section{Source}

National Cancer Institute. Protein/Amino Acid Biochemistry, Enzymology. NCI Thesaurus.

Code C18973.

The enzymes involved in the metabolism of proteins and amino acids. 